\title{
Aggressiveness Niche: Can It Be the Foster Ground for Cancer Metastasis Precursors?
}

\author{
Wael M. ElShamy, ${ }^{1}$ Abhilasha Sinha, ${ }^{1}$ and Neveen Said ${ }^{2}$ \\ ${ }^{1}$ Cancer Institute, University of Mississippi Medical Center, Jackson, MS, USA \\ ${ }^{2}$ Department of Cancer Biology and Comprehensive Cancer Center, Wake Forest University School of Medicine, \\ Winston-Salem, NC, USA \\ Correspondence should be addressed to Wael M. ElShamy; welshamy@umc.edu
}

Received 30 March 2016; Accepted 15 June 2016

Academic Editor: Zhaohui Ye

Copyright (C) 2016 Wael M. ElShamy et al. This is an open access article distributed under the Creative Commons Attribution License, which permits unrestricted use, distribution, and reproduction in any medium, provided the original work is properly cited.

The relationship between tumor initiation and tumor progression can follow a linear projection in which all tumor cells are equally endowed with the ability to progress into metastasis. Alternatively, not all tumor cells are equal genetically and/or epigenetically, and only few cells are induced to become metastatic tumor cells. The location of these cells within the tumor can also impact the fate of these cells. The most inner core of a tumor where an elevated pressure of adverse conditions forms, such as necrosisinduced inflammation and hypoxia-induced immunosuppressive environment, seems to be the most fertile ground to generate such tumor cells with metastatic potential. Here we will call this necrotic/hypoxic core the "aggressiveness niche" and will present data to support its involvement in generating these metastatic precursors. Within this niche, interaction of hypoxia-surviving cells with the inflammatory microenvironment influenced by newly recruited mesenchymal stromal cells (MSCs), tumor-associated macrophages (TAMs), and other types of cells and the establishment of bidirectional interactions between them elevate the aggressiveness of these tumor cells. Additionally, immune evasion properties induced in these cells most likely contribute in the formation and maintenance of such aggressiveness niche.

\section{Introduction}

Tumor cells disseminate from primaries following a complex and stepwise process involving invading surrounding tissues, intravasation, and survival in the circulation, extravasation, and survival in a distant and foreign metastatic sites [1]. These monumental tasks require that tumor cells undergo several changes, such as transitioning from epithelial to mesenchymal (EMT), to be able to detach from primary site's extracellular matrix (ECM), migrate and invade surrounding tissues, and develop strategies to resist anoikis and the sheer forces within the circulatory system $[2,3]$. Understanding these mechanisms and events that help generate such cells will benefit the design of therapies targeting disseminating cells and prevent cancer metastasis. Here, we propose an "aggressiveness niche" minimally defined as the necrotic/hypoxic core in tumors, within which recruited and activated mesenchymal stem cells (MSCs), tumor-associated macrophages (TAMs), and other stromal and inflammatory cells through bidirectional interactions entrain tumor cells to become metastasis precursors. These interactions also help generate conducive microenvironment for such entrainment.

\section{The Role of Necrosis-Induced Inflammation in Aggressiveness Niche Formation}

In aggressive tumors, the rate of proliferation exceeds that of neoangiogenesis leading to necrosis, especially within tumors cores. Unlike apoptotic cells, necrotic cells do not signal to nearby phagocytes to engulf and recycle them. Instead, intracellular content, including damage-associated molecular pattern (DAMP) materials, spills into the microenvironment leading to increase in inflammation within these cores.

High mobility group binding (HMGB1) protein is wellstudied DAMP normally bound to chromatin [4]. HMGB1 can be passively released from necrotic, autophagic, and 


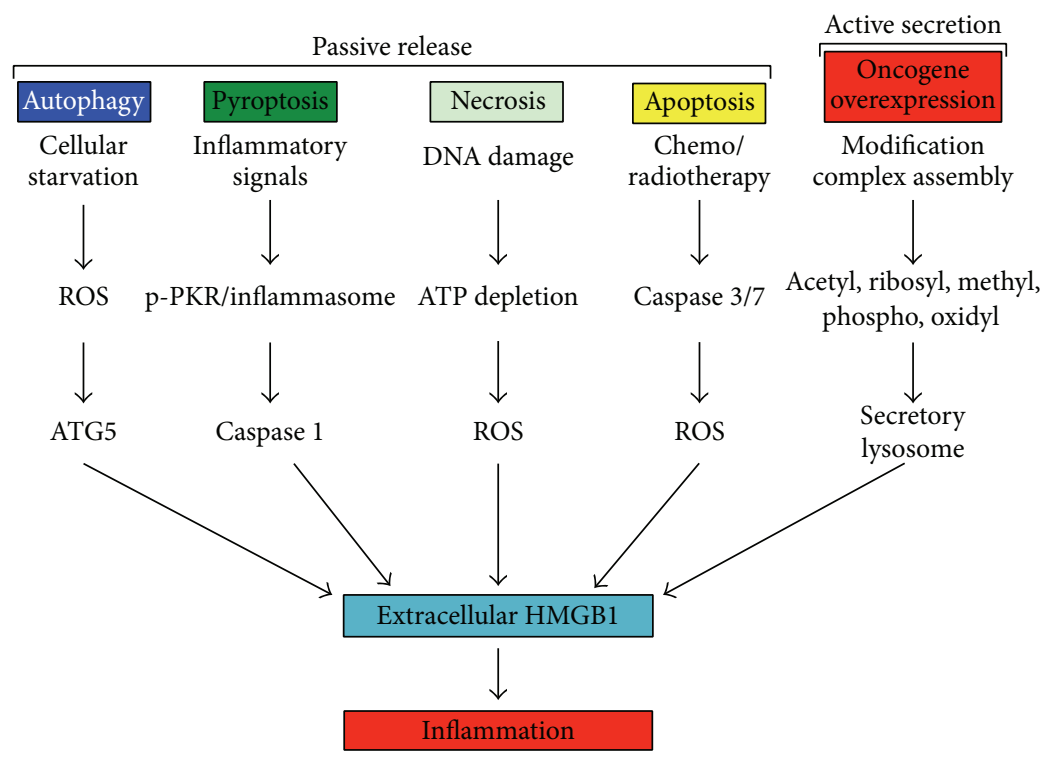

Figure 1: HMGB1 and inflammation. The forces contributing to the passive release and the active secretion of HMGB1 from tumor cells within the aggressiveness niche.

apoptotic cells $[5,6]$ or actively secreted from oncogeneactivated tumor cells [7] (Figure 1). Modifications such as methylation, glycosylation, ribosylation, and acetylation promote release from chromatin and the cytokine function of HMGB1 [8-11].

Extracellular HMGB1 binds in either autocrine or paracrine manner to several cell surface receptors, including receptor for advanced glycation end products (RAGE) and toll-like receptors (TLRs) [12-15]. Binding to these receptors activates proinflammatory signaling pathways, such as the NF- $\kappa \mathrm{B}$, IFN regulatory factor-3 (IRF3), phosphoinositide 3-kinase (PI3K), and inflammasome to induce proinflammatory cytokine release into the microenvironment [16, 17]. Therefore, extracellular HMGB1 sustains an inflammatory microenvironment within tumors that supports tumor growth, invasion, and metastasis [18-22]. Indeed, several studies showed that inhibiting HMGB1-RAGE or HMGB1TLR4 interactions suppresses inflammation, tumor growth, and metastasis in animal models [18, 23]. Additionally, in the clinic, expression of RAGE or TLR4 is closely associated with invasion and metastasis [21, 22]. Accordingly, neutralizing HMGB1 antibody or RAGE knockdown inhibited tumor angiogenesis and metastasis in vitro and in vivo [22]. Furthermore, chemotherapies promote cell death in tumors concurrently with sequestration of HMGB1 in the nucleus, preventing its release even if necrotic death ensues.

Another powerful factor spilled out of necrotic cells is ATP [24]. ATP activation of the P2X7 purinergic receptor on tumor cells in autocrine or paracrine fashion leads to fall in the intracellular potassium level, which triggers the oligomerization of the "inflammasome" [25]. The inflammasome contains proteins, such as cryopyrin or nucleotidebinding domain and leucine-rich repeat containing protein 3 (NLRP3) and procaspase 1. The inflammasome processes procaspase 1 into an active cysteine protease "caspase 1" [26].
Caspase 1 then binds and cleaves IL- $1 \beta$ precursor converting it to the active secreted form [27]. Caspase 1 is constitutively active in highly metastatic human cancers, especially those with mutation in cryopyrin $[28,29]$. The activation of inflammasomes and their downstream targets contribute to innate and adaptive immunologic defense mechanisms by the regulation of several different and partially opposing pathways [30].

The adaptive immune system is divided into $\mathrm{CD} 4^{+}$and $\mathrm{CD}^{+}{ }^{\mathrm{T}} \mathrm{T}$-cell lineages. Activation through unique T-cell receptors (TCRs) and costimulation by antigen-presenting cells (APCs), such as dendritic cells (DCs), rapidly enhance T-cells proliferation and differentiation into effector cells. Effector $\mathrm{CD} 4^{+}$T-cells develop as interferon $-\gamma($ IFN- $\gamma$ ) producing $\mathrm{T}$ helper cells $\left(\mathrm{Th}_{1}\right)$, IL-4/IL-13 producing $\mathrm{Th}_{2}$ cells, IL-10 producing regulatory $\mathrm{T}\left(\mathrm{T}_{\text {reg }}\right)$ cells, and IL-17 producing $\mathrm{Th}_{17}$ cells. $\mathrm{CD}^{+} \mathrm{T}$-cells are mainly considered cytotoxic $\mathrm{T}$ lymphocytes (CTLs) and produce cytotoxic granules that kill cancerous cells. Extracellular HMGB1 induces apoptosis in DCs, thus suppressing $\mathrm{CD}^{+} \mathrm{T}$-cells function and enhancing $\mathrm{T}_{\text {reg }}$ function and diminishing host anticancer immunity within the necrotic core $[31,32]$, which lead to tumor progression [33]. Extracellular IL-1 $\beta$ induces accumulation of myeloid-derived suppressor cells (MDSCs) that impairs NK cells development and functions in vitro and in vivo [34]. MDSCs contribute to tumor progression and growth by suppressing antitumor immune responses via blocking $\mathrm{CD}^{+}$and $\mathrm{CD}^{+}{ }^{+}$-cells activation [35]. Taken together, these findings highlight the potential important role of necrosis in the development of the aggressiveness niche, in which an inflammatory environment provides an immune evasion response leading to cancer progression. In fact, recent clinical trial showed great efficacy for the anti-IL- $1 \beta$ monoclonal antibody "anakinra" [36]. 


\section{The Role of Hypoxia-Induced Adaptation in Aggressiveness Niche Formation}

In a fast-growing tumor, the diffusion distance from the existing vascular supply increases resulting in hypoxia [37, 38]. Hypoxia affects tumors in many ways including enhancing cell growth rate, neovascularization, metastasis, and resistance to treatment.

In cancer tissues, large areas of hypoxic tissue and concentration of the hypoxic markers, such as CAIX and HIF$1 \alpha$ exist around necrotic regions. HIF- 1 family of basic helixloop-helix transcription factors includes HIF- $1 \alpha$, HIF- $2 \alpha$, and HIF-3 $\alpha$ [39]. Only HIF- $1 \alpha$ is destabilized and degraded under normoxic conditions, whereas, under hypoxic conditions, it is stabilized and translocated to the nucleus to heterodimerize with the constitutively expressed HIF- $1 \beta[40,41]$. The HIF$1 \alpha$-HIF-1 $\beta$ complex through binding to HIF response elements (HREs) in the promoter regions of important adaptive genes activates their transcription [42-46].

Hypoxia also promotes metabolic shift and lowers the $\mathrm{pH}$ within the aggressiveness niche impeding the adaptive immune response and acts to recruit immune suppressive cells, such as MDSCs, $\mathrm{T}_{\text {regs }}$ that significantly reduce $\mathrm{CD} 4^{+}$ T-cell proliferation, $\mathrm{CD}^{+} \mathrm{T}$-cell, and natural killer (NK) cells cytotoxicity [47-50]. The anaerobic conditions within the aggressiveness niche ferment the pyruvate produced by glucose metabolism in tumor cells into acidic lactate, which helps altering the metabolism in the niche in what is called "Warburg effect" [51]. The Warburg effect also suppresses the maturation of antigen-presenting cells (APCs) that activate naïe T-cells [52]. Taken together, these findings highlight the potential important role of hypoxia in generating an immune suppressive microenvironment and together with the necrotic microenvironment maintain an immune evasion response that promotes cancer progression.

\section{The Role of MSCs in Aggressiveness Niche Formation}

MSCs are primitive cells mobilized from the bone marrow to sites of hematopoiesis, inflammation, injury, and solid tumors [53-56]. Within these sites MSCs differentiate to give rise to cells of many lineages, including muscle, bone, fat, and cartilage lineages [57, 58]. Recent data also point to the fact that, within tumors, MSCs can differentiate into carcinoma-associated fibroblasts (CAFs) [59-66]. CAFs' role in enhancing tumor growth, progression, metastasis, and therapeutic resistance has been shown in many cancers [6769].

The aggressiveness niche resembles, to a great extent, tissues undergoing chronic inflammation [70]. This causes immune response leading to homing of MSCs to aggressiveness niche in response to chemotactic factors, such as the monocyte chemotactic protein-1 (MCP-1) [71], cyclophilin B, the hepatoma-derived growth factor (HDGF) [72], and IL-6 [73], and activation of intracellular signaling in MSCs, such as STAT3. Cancer cells, especially those with cancer stem-like cells (CSCs) activity [74, 75], such as triple negative breast cancer cells (TNBCs), secret effector cytokines, including
IFN- $\gamma$, TNF- $\alpha$, and IL- $1 \beta$ that activate MSCs immunosuppressive role [76, 77]. Activated MSCs then produce many immune-modulatory molecules such as hepatocyte growth factor (HGF), transforming growth factor- $\beta$ (TGF- $\beta$ ), prostaglandin E2 (PGE2), IL-10, and inducible nitric oxide synthase (iNOS) [78-82]. These cytokines suppress IFN- $\gamma$ production from $\mathrm{Th}_{1}$, promote IL- 4 secretion from $\mathrm{Th}_{2}$, and increase T-cells polarization more towards TGF- $\beta$-expressing $\mathrm{T}_{\text {reg }}$ cells, rather than IL-17-expressing $\mathrm{Th}_{17}$ cells [78-82], thus generating immunosuppressive environment that promotes tumor cells aggressiveness within the niche.

Furthermore, MSCs express the major histocompatibility complex (MHC) class I but lack class II MHC along with the costimulatory molecules CD80, CD86, and CD40 [83, 84]. MSCs can suppress T-cell proliferation and activation in response to allogeneic antigens [82], inhibit B-cell proliferation, differentiation, and antibody generation [85], interfere with DCs maturation and function $[86,87]$, recruit $\mathrm{CD}^{+}{ }^{+}$oxp $3^{+} \mathrm{CD} 25^{+} \mathrm{T}_{\text {reg }}$, and promote their proliferation. Taken together, these studies demonstrate the profound effect of MSCs in exacerbating tumor progression through bidirectional interactions with tumor cells [67] or indirectly through effects on the tumor microenvironment $[63,66]$.

\section{The Role of TAMs in Aggressiveness Niche Formation}

Monocytes also originate from the bone marrow, where they enter the peripheral blood and infiltrate into tumors [88]. In breast cancers, nearly half the tumor mass consists of tumor-associated macrophages (TAMs). In tumors, TAMs accumulation associates with disease progression and is often correlated with poor prognosis [89]. Within tumors, monocytes can differentiate into specialized phagocytes M1-macrophages that engulf and digest dead and tumor cells or into pro-tumor M2-polarized macrophages. M1macrophages primed by IFN- $\gamma$ could be activated by tumor necrosis factor- $\alpha$ (TNF- $\alpha$ ) or by activation of toll-like receptors (TLRs) via exposure to microbes or microbial products such as bacterial LPS [90]. M1-polarized macrophages could also function as antigen-presenting cells [91] and secrete high levels of inhibitory interleukin-12 (IL-12) and IL-23 cytokines [92]. On the other hand, in the presence of cytokines, such as IL-4 and IL-13, macrophages differentiate into immunosuppressive M2-macrophages characterized by IL-10 production that promotes tumor progression $[90,93]$.

Like MSCs, TAMs generally accumulate in hypoxic areas of the tumor. MSCs skew macrophages towards the M2-polarization in vivo leading to increase in IL-10 production and decreased proinflammatory cytokine and NO production in tumors, which leads to immunosuppressive environment instead of initiating T-cell-mediated immune responses within tumors $[79,86]$. Prostaglandin E2 (PGE2) constitutively produced by human MSCs suppresses IL-6 and TNF- $\alpha$ expression in macrophages. In addition, neutralizing antibodies to IL-6 and granulocyte macrophage-colony stimulating factor (GM-CSF) showed that these cytokines synergistically promote human gingiva-derived MSC-mediated promotion of the M2 phenotype in macrophages [89-93]. 
Other immune system entities such as mast cells, neutrophils, NK cells, and dendritic cells (DCs) contribute to breast tumor progression, especially through the release of proinflammatory cytokines. MSCs also reduced inflammation promoted by mast cells and were resistant to cytotoxicity by NKs. Neutralization of PGE2 and transforming growth factor- $\beta$ (TGF- $\beta$ ), both thought to contribute to MSC immunosuppression, overrode MSC-mediated suppression of NK proliferation. MSCs also interfere with DC maturation, IL-12 production, and migration to lymph nodes in vivo, leading to insufficient T-cell priming in the lymph nodes [31].

\section{Concluding Remarks}

There is a complicated interplay between cancer and the host immune system. Understanding this interplay and the mechanisms by which tumors evade immune control should identify new and innovative therapeutic strategies. Reversing these immune evasion strategies could strengthen the adoptive immune system as a promising tool for cancer therapy. Additionally, understanding all the mechanisms tumors use to establish growth and subsequently metastasize, in part through evasion of immune surveillance, for example, the role of MSCs in such evasion, could help in generating combinatorial therapies that provide therapeutic efficacy by preventing the suppressive effect of MSCs and activating the antitumor effect of the immune system. It should be noted, however, that experimental evidences that support the notion that cells within the niche are those that form the metastasis are still lacking.

\section{Competing Interests}

The authors declare that they have no competing interests.

\section{Acknowledgments}

The authors would like to thank all the members of the ElShamy's Laboratory for valuable comments and discussions. This work is supported by the National Cancer Institute Grants R01 CA194447 (Wael M. ElShamy).

\section{References}

[1] D. Hanahan and R. A. Weinberg, "The hallmarks of cancer," Cell, vol. 100, no. 1, pp. 57-70, 2000.

[2] M. Luo, M. Brooks, and M. S. Wicha, "Epithelial-mesenchymal plasticity of breast cancer stem cells: implications for metastasis and therapeutic resistance," Current Pharmaceutical Design, vol. 21, no. 10, pp. 1301-1310, 2015.

[3] D. J. Drasin, T. P. Robin, and H. L. Ford, "Breast cancer epithelial-to-mesenchymal transition: examining the functional consequences of plasticity," Breast Cancer Research, vol. 13, no. 6, article 226, 2011.

[4] B. Sangiuliano, N. M. Pérez, D. F. Moreira, and J. E. Belizário, "Cell death-associated molecular-pattern molecules: inflammatory signaling and control," Mediators of Inflammation, vol. 2014, Article ID 821043, 14 pages, 2014.
[5] P. Scaffidi, T. Misteli, and M. E. Bianchi, "Release of chromatin protein HMGB1 by necrotic cells triggers inflammation," Nature, vol. 418, no. 6894, pp. 191-195, 2002.

[6] D. Tang, R. Kang, K. M. Livesey et al., "Endogenous HMGB1 regulates autophagy," Journal of Cell Biology, vol. 190, no. 5, pp. 881-892, 2010.

[7] S. Ananthula, A. Sinha, M. E. Gassim et al., "Geminin overexpression-dependent recruitment and crosstalk with mesenchymal stem cells enhance aggressiveness in triple negative breast cancers," Oncotarget, 2016.

[8] F. Wu, Z.-H. Zhao, S.-T. Ding, H.-H. Wu, and J.-J. Lu, "High mobility group box 1 protein is methylated and transported to cytoplasm in clear cell renal cell carcinoma," Asian Pacific Journal of Cancer Prevention, vol. 14, no. 10, pp. 5789-5795, 2013.

[9] Y. H. Kim, M. S. Kwak, J. B. Park et al., "N-linked glycosylation plays a crucial role in the secretion of HMGB1," Journal of Cell Science, vol. 129, no. 1, pp. 29-38, 2016.

[10] K. Davis, S. Banerjee, A. Friggeri, C. Bell, E. Abraham, and M. Zerfaoui, "Poly(ADP-Ribosyl)ation of high mobility group box 1 (HMGB1) protein enhances inhibition of efferocytosis," Molecular Medicine, vol. 18, no. 3, pp. 359-369, 2012.

[11] I. Ugrinova, E. A. Pasheva, J. Armengaud, and I. G. Pashev, "In vivo acetylation of HMG1 protein enhances its binding affinity to distorted DNA structures," Biochemistry, vol. 40, no. 48, pp. 14655-14660, 2001.

[12] R. Kang, D. Tang, N. E. Schapiro et al., "The HMGB1/RAGE inflammatory pathway promotes pancreatic tumor growth by regulating mitochondrial bioenergetics," Oncogene, vol. 33, no. 5, pp. 567-577, 2014

[13] M. T. Lotze and K. J. Tracey, "High-mobility group box 1 protein (HMGB1): nuclear weapon in the immune arsenal," Nature Reviews Immunology, vol. 5, no. 4, pp. 331-342, 2005.

[14] D. Tang, R. Kang, C. B. Coyne, H. J. Zeh, and M. T. Lotze, "PAMPs and DAMPs: signal 0s that spur autophagy and immunity," Immunological Reviews, vol. 249, no. 1, pp. 158-175, 2012.

[15] H. Yang, H. S. Hreggvidsdottir, K. Palmblad et al., "A critical cysteine is required for HMGB1 binding to toll-like receptor 4 and activation of macrophage cytokine release," Proceedings of the National Academy of Sciences of the United States of America, vol. 107, no. 26, pp. 11942-11947, 2010.

[16] C. Gebhardt, A. Riehl, M. Durchdewald et al., "RAGE signaling sustains inflammation and promotes tumor development," The Journal of Experimental Medicine, vol. 205, no. 2, pp. 275-285, 2008.

[17] L. Campana, L. Bosurgi, and P. Rovere-Querini, "HMGB1: a two-headed signal regulating tumor progression and immunity," Current Opinion in Immunology, vol. 20, no. 5, pp. 518-523, 2008.

[18] A. Taguchi, D. C. Blood, G. del Toro et al., "Blockade of RAGE-amphoterin signalling suppresses tumour growth and metastases," Nature, vol. 405, no. 6784, pp. 354-360, 2000.

[19] J. Heijmans, N. V. J. A. Büller, E. Hoff et al., "Rage signalling promotes intestinal tumourigenesis," Oncogene, vol. 32, no. 9, pp. 1202-1206, 2013.

[20] R. Kang, T. Loux, D. Tang et al., "The expression of the receptor for advanced glycation endproducts (RAGE) is permissive for early pancreatic neoplasia," Proceedings of the National Academy of Sciences of the United States of America, vol. 109, no. 18, pp. 7031-7036, 2012. 
[21] H. Kuniyasu, N. Oue, A. Wakikawa et al., "Expression of receptors for advanced glycation end-products (RAGE) is closely associated with the invasive and metastatic activity of gastric cancer," The Journal of Pathology, vol. 196, no. 2, pp. 163-170, 2002.

[22] T. Sasahira, Y. Akama, K. Fujii, and H. Kuniyasu, "Expression of receptor for advanced glycation end products and HMGB1/amphoterin in colorectal adenomas," Virchows Archiv, vol. 446, no. 4, pp. 411-415, 2005.

[23] A. Tsung, R. Sahai, H. Tanaka et al., "The nuclear factor HMGB1 mediates hepatic injury after murine liver ischemiareperfusion," Journal of Experimental Medicine, vol. 201, no. 7, pp. 1135-1143, 2005.

[24] D. G. Perregaux, P. McNiff, R. Laliberte, M. Conklyn, and C. A. Gabel, "ATP acts as an agonist to promote stimulusinduced secretion of IL-1 $\beta$ and IL-18 in human blood," Journal of Immunology, vol. 165, no. 8, pp. 4615-4623, 2000.

[25] L. Agostini, F. Martinon, K. Burns, M. F. McDermott, P. N. Hawkins, and J. Tschopp, "NALP3 forms an IL-1 $\beta$-processing inflammasome with increased activity in Muckle-Wells autoinflammatory disorder," Immunity, vol. 20, no. 3, pp. 319-325, 2004.

[26] M. Gattorno, S. Tassi, S. Carta et al., "Pattern of interleukin-1 $\beta$ secretion in response to lipopolysaccharide and ATP before and after interleukin-1 blockade in patients with CIAS1 mutations," Arthritis and Rheumatism, vol. 56, no. 9, pp. 3138-3148, 2007.

[27] G. Kroemer, L. Galluzzi, O. Kepp, and L. Zitvogel, "Immunogenic cell death in cancer therapy," Annual Review of Immunology, vol. 31, pp. 51-72, 2013.

[28] H. M. Hoffman, J. L. Mueller, D. H. Broide, A. A. Wanderer, and R. D. Kolodner, "Mutation of a new gene encoding a putative pyrin-like protein causes familial cold autoinflammatory syndrome and Muckle-Wells syndrome," Nature Genetics, vol. 29, no. 3, pp. 301-305, 2001.

[29] M. Okamoto, W. Liu, Y. Luo et al., "Constitutively active inflammasome in human melanoma cells mediating autoinflammation via caspase-1 processing and secretion of interleukin-1 $\beta$," The Journal of Biological Chemistry, vol. 285, no. 9, pp. 64776488, 2010.

[30] G. Sollberger, G. E. Strittmatter, M. Garstkiewicz, J. Sand, and H.-D. Beer, "Caspase-1: the inflammasome and beyond," Innate Immunity, vol. 20, no. 2, pp. 115-125, 2014.

[31] A. Kusume, T. Sasahira, Y. Luo et al., "Suppression of dendritic cells by HMGB1 is associated with lymph node metastasis of human colon cancer," Pathobiology, vol. 76, no. 4, pp. 155-162, 2009.

[32] Z. Liu, L. D. Falo Jr., and Z. You, "Knockdown of HMGB1 in tumor cells attenuates their ability to induce regulatory $\mathrm{T}$ cells and uncovers naturally acquired CD8 T cell-dependent antitumor immunity," The Journal of Immunology, vol. 187, no. 1, pp. 118-125, 2011.

[33] Y. He, J. Zha, Y. Wang, W. Liu, X. Yang, and P. Yu, “Tissue damage-associated 'danger signals' influence T-cell responses that promote the progression of preneoplasia to cancer," Cancer Research, vol. 73, no. 2, pp. 629-639, 2013.

[34] M. Elkabets, V. S. G. Ribeiro, C. A. Dinarello et al., "IL-1 $\beta$ regulates a novel myeloid-derived suppressor cell subset that impairs NK cell development and function," European Journal of Immunology, vol. 40, no. 12, pp. 3347-3357, 2010.

[35] S. K. Bunt, V. K. Clements, E. M. Hanson, P. Sinha, and S. Ostrand-Rosenberg, "Inflammation enhances myeloid-derived suppressor cell cross-talk by signaling through Toll-like receptor 4," Journal of Leukocyte Biology, vol. 85, no. 6, pp. 996-1004, 2009.

[36] C. A. Dinarello and J. W. M. van der Meer, "Treating inflammation by blocking interleukin-1 in humans," Seminars in Immunology, vol. 25, no. 6, pp. 469-484, 2013.

[37] M. Tafani, L. Schito, L. Pellegrini et al., "Hypoxia-increased RAGE and P2X7R expression regulates tumor cell invasion through phosphorylation of Erk1/2 and Akt and nuclear translocation of NF- $\kappa$ B," Carcinogenesis, vol. 32, no. 8, pp. 11671175, 2011.

[38] W. Yan, Y. Chang, X. Liang et al., "High-mobility group box 1 activates caspase-1 and promotes hepatocellular carcinoma invasiveness and metastases," Hepatology, vol. 55, no. 6, pp. 1863-1875, 2012.

[39] P. J. Ratcliffe, "HIF-1 and HIF-2: working alone or together in hypoxia?" The Journal of Clinical Investigation, vol. 117, no. 4, pp. 862-865, 2007.

[40] R. K. Bruick, "Oxygen sensing in the hypoxic response pathway: regulation of the hypoxia-inducible transcription factor," Genes and Development, vol. 17, no. 21, pp. 2614-2623, 2003.

[41] C. J. Schofield and P. J. Ratcliffe, "Oxygen sensing by HIF hydroxylases," Nature Reviews Molecular Cell Biology, vol. 5, no. 5, pp. 343-354, 2004.

[42] R. H. Wenger, D. P. Stiehl, and G. Camenisch, "Integration of oxygen signaling at the consensus HRE," Science's STKE, vol. 2005, no. 306, article re12, 2005.

[43] C. J. Fox, P. S. Hammerman, and C. B. Thompson, "Fuel feeds function: energy metabolism and the T-cell response," Nature Reviews Immunology, vol. 5, no. 11, pp. 844-852, 2005.

[44] D. J. Kominsky, E. L. Campbell, and S. P. Colgan, "Metabolic shifts in immunity and inflammation," Journal of Immunology, vol. 184, no. 8, pp. 4062-4068, 2010.

[45] V. Nizet and R. S. Johnson, "Interdependence of hypoxic and innate immune responses," Nature Reviews Immunology, vol. 9, no. 9, pp. 609-617, 2009.

[46] C. T. Taylor and S. P. Colgan, "Hypoxia and gastrointestinal disease," Journal of Molecular Medicine, vol. 85, no. 12, pp. 12951300, 2007.

[47] Y. Makino, H. Nakamura, E. Ikeda et al., "Hypoxia-inducible factor regulates survival of antigen receptor-driven T cells," The Journal of Immunology, vol. 171, no. 12, pp. 6534-6540, 2003.

[48] H. Nakamura, Y. Makino, K. Okamoto et al., "TCR engagement increases hypoxia-inducible factor- $1 \alpha$ protein synthesis via rapamycin-sensitive pathway under hypoxic conditions in human peripheral T cells," The Journal of Immunology, vol. 174, no. 12, pp. 7592-7599, 2005.

[49] M. Sitkovsky and D. Lukashev, "Regulation of immune cells by local-tissue oxygen tension: HIF1 $\alpha$ and adenosine receptors," Nature Reviews Immunology, vol. 5, no. 9, pp. 712-721, 2005.

[50] A. K. Neumann, J. Yang, M. P. Biju et al., "Hypoxia inducible factor $1 \alpha$ regulates T cell receptor signal transduction," Proceedings of the National Academy of Sciences of the United States of America, vol. 102, no. 47, pp. 17071-17076, 2005.

[51] F. Sotgia, U. E. Martinez-Outschoorn, S. Pavlides, A. Howell, R. G. Pestell, and M. P. Lisanti, "Understanding the Warburg effect and the prognostic value of stromal caveolin-1 as a marker of a lethal tumor microenvironment," Breast Cancer Research, vol. 13, no. 4, article 213, 2011.

[52] Z. Husain, Y. Huang, P. Seth, and V. P. Sukhatme, "Tumorderived lactate modifies antitumor immune response: effect on 
myeloid-derived suppressor cells and NK cells," The Journal of Immunology, vol. 191, no. 3, pp. 1486-1495, 2013.

[53] S. C. Mendes, C. Robin, and E. Dzierzak, "Mesenchymal progenitor cells localize within hematopoietic sites throughout ontogeny," Development, vol. 132, no. 5, pp. 1127-1136, 2005.

[54] V. Sordi, M. L. Malosio, F. Marchesi et al., "Bone marrow mesenchymal stem cells express a restricted set of functionally active chemokine receptors capable of promoting migration to pancreatic islets," Blood, vol. 106, no. 2, pp. 419-427, 2005.

[55] A. Giordano, U. Galderisi, and I. R. Marino, "From the laboratory bench to the patient's bedside: an update on clinical trials with mesenchymal stem cells," Journal of Cellular Physiology, vol. 211, no. 1, pp. 27-35, 2007.

[56] M. Studeny, F. C. Marini, J. L. Dembinski et al., "Mesenchymal stem cells: potential precursors for tumor stroma and targeteddelivery vehicles for anticancer agents," Journal of the National Cancer Institute, vol. 96, no. 21, pp. 1593-1603, 2004.

[57] S. C. Picinich, P. J. Mishra, P. J. Mishra, J. Glod, and D. Banerjee, "The therapeutic potential of mesenchymal stem cells," Expert Opinion on Biological Therapy, vol. 7, no. 7, pp. 965-973, 2007.

[58] M. F. Pittenger, A. M. Mackay, S. C. Beck et al., "Multilineage potential of adult human mesenchymal stem cells," Science, vol. 284, no. 5411, pp. 143-147, 1999.

[59] M. J. Bissell and D. Radisky, "Putting tumours in context," Nature Reviews Cancer, vol. 1, no. 1, pp. 46-54, 2001.

[60] A. Orimo, P. B. Gupta, D. C. Sgroi et al., "Stromal fibroblasts present in invasive human breast carcinomas promote tumor growth and angiogenesis through elevated SDF-1/CXCL12 secretion," Cell, vol. 121, no. 3, pp. 335-348, 2005.

[61] N. C. Direkze, K. Hodivala-Dilke, R. Jeffery et al., "Bone marrow contribution to tumor-associated myofibroblasts and fibroblasts," Cancer Research, vol. 64, no. 23, pp. 8492-8495, 2004.

[62] P. J. Mishra, P. J. Mishra, R. Humeniuk et al., "Carcinomaassociated fibroblast-like differentiation of human mesenchymal stem cells," Cancer Research, vol. 68, no. 11, pp. 4331-4339, 2008.

[63] E. L. Spaeth, J. L. Dembinski, A. K. Sasser et al., "Mesenchymal stem cell transition to tumor-associated fibroblasts contributes to fibrovascular network expansion and tumor progression," PLoS ONE, vol. 4, no. 4, Article ID e4992, 2009.

[64] J. L. Spees, S. D. Olson, J. Ylostalo et al., "Differentiation, cell fusion, and nuclear fusion during ex vivo repair of epithelium by human adult stem cells from bone marrow stroma," Proceedings of the National Academy of Sciences of the United States of America, vol. 100, no. 5, pp. 2397-2402, 2003.

[65] S. A. Kuznetsov, P. H. Krebsbach, K. Satomura et al., "Singlecolony derived strains of human marrow stromal fibroblasts form bone after transplantation in vivo," Journal of Bone and Mineral Research, vol. 12, no. 9, pp. 1335-1347, 1997.

[66] D. J. Prockop, C. A. Gregory, and J. L. Spees, “One strategy for cell and gene therapy: harnessing the power of adult stem cells to repair tissues," Proceedings of the National Academy of Sciences of the United States of America, vol. 100, supplement 1, pp. 1191711923, 2003.

[67] A. E. Karnoub, A. B. Dash, A. P. Vo et al., "Mesenchymal stem cells within tumour stroma promote breast cancer metastasis," Nature, vol. 449, no. 7162, pp. 557-563, 2007.

[68] A. Y. Khakoo, S. Pati, S. A. Anderson et al., "Human mesenchymal stem cells exert potent antitumorigenic effects in a model of Kaposi's sarcoma," The Journal of Experimental Medicine, vol. 203, no. 5, pp. 1235-1247, 2006.
[69] P. A. Toste, A. H. Nguyen, B. E. Kadera et al., "Chemotherapyinduced inflammatory gene signature and protumorigenic phenotype in pancreatic CAFs via stress-associated MAPK," Molecular Cancer Research, vol. 14, no. 5, pp. 437-447, 2016.

[70] H. F. Dvorak, "Tumors: wounds that do not heal," The New England Journal of Medicine, vol. 315, no. 26, pp. 1650-1659, 1986.

[71] R. M. Dwyer, S. M. Potter-Beirne, K. A. Harrington et al., "Monocyte chemotactic protein-1 secreted by primary breast tumors stimulates migration of mesenchymal stem cells," Clinical Cancer Research, vol. 13, no. 17, pp. 5020-5027, 2007.

[72] S.-Y. Lin, J. Yang, A. D. Everett et al., "The isolation of novel mesenchymal stromal cell chemotactic factors from the conditioned medium of tumor cells," Experimental Cell Research, vol. 314, no. 17, pp. 3107-3117, 2008.

[73] Y. Rattigan, J.-M. Hsu, P. J. Mishra, J. Glod, and D. Banerjee, "Interleukin 6 mediated recruitment of mesenchymal stem cells to the hypoxic tumor milieu," Experimental Cell Research, vol. 316, no. 20, pp. 3417-3424, 2010.

[74] K. E. Hatzistergos, H. Quevedo, B. N. Oskouei et al., "Bone marrow mesenchymal stem cells stimulate cardiac stem cell proliferation and differentiation," Circulation Research, vol. 107, no. 7, pp. 913-922, 2010.

[75] J. M. Sorrell and A. I. Caplan, "Topical delivery of mesenchymal stem cells and their function in wounds," Stem Cell Research and Therapy, vol. 1, no. 4, article 30, 2010.

[76] F. Djouad, P. Plence, C. Bony et al., "Immunosuppressive effect of mesenchymal stem cells favors tumor growth in allogeneic animals," Blood, vol. 102, no. 10, pp. 3837-3844, 2003.

[77] F. Djouad, C. Bony, F. Apparailly, P. Louis-Plence, C. Jorgensen, and D. Noël, "Earlier onset of syngeneic tumors in the presence of mesenchymal stem cells," Transplantation, vol. 82, no. 8, pp. 1060-1066, 2006.

[78] A. Corcione, F. Benvenuto, E. Ferretti et al., "Human mesenchymal stem cells modulate B-cell functions," Blood, vol. 107, no. 1, pp. 367-372, 2006.

[79] W. Deng, Q. Han, L. Liao, S. You, H. Deng, and R. C. H. Zhao, "Effects of allogeneic bone marrow-derived mesenchymal stem cells on T and B lymphocytes from BXSB mice," DNA and Cell Biology, vol. 24, no. 7, pp. 458-463, 2005.

[80] M. Di Nicola, C. Carlo-Stella, M. Magni et al., "Human bone marrow stromal cells suppress T-lymphocyte proliferation induced by cellular or nonspecific mitogenic stimuli," Blood, vol. 99, no. 10, pp. 3838-3843, 2002.

[81] S. Glennie, I. Soeiro, P. J. Dyson, E. W.-F. Lam, and F. Dazzi, "Bone marrow mesenchymal stem cells induce division arrest anergy of activated T cells," Blood, vol. 105, no. 7, pp. 2821-2827, 2005.

[82] M. Sioud, A. Mobergslien, A. Boudabous, and Y. Fløisand, "Evidence for the involvement of galectin-3 in mesenchymal stem cell suppression of allogeneic T-cell proliferation," Scandinavian Journal of Immunology, vol. 71, no. 4, pp. 267-274, 2010.

[83] M. Dominici, K. Le Blanc, I. Mueller et al., "Minimal criteria for defining multipotent mesenchymal stromal cells. The International Society for Cellular Therapy position statement," Cytotherapy, vol. 8, no. 4, pp. 315-317, 2006.

[84] V. D. Roobrouck, F. Ulloa-Montoya, and C. M. Verfaillie, "Selfrenewal and differentiation capacity of young and aged stem cells," Experimental Cell Research, vol. 314, no. 9, pp. 1937-1944, 2008 . 
[85] F. Djouad, L.-M. Charbonnier, C. Bouffi et al., "Mesenchymal stem cells inhibit the differentiation of dendritic cells through an interleukin-6-dependent mechanism," STEM CELLS, vol. 25, no. 8, pp. 2025-2032, 2007.

[86] X.-X. Jiang, Y. Zhang, B. Liu et al., "Human mesenchymal stem cells inhibit differentiation and function of monocyte-derived dendritic cells," Blood, vol. 105, no. 10, pp. 4120-4126, 2005.

[87] R. Ramasamy, H. Fazekasova, E. W.-F. Lam, I. Soeiro, G. Lombardi, and F. Dazzi, "Mesenchymal stem cells inhibit dendritic cell differentiation and function by preventing entry into the cell cycle," Transplantation, vol. 83, no. 1, pp. 71-76, 2007.

[88] S. Gordon and P. R. Taylor, "Monocyte and macrophage heterogeneity," Nature Reviews Immunology, vol. 5, no. 12, pp. 953-964, 2005.

[89] C. E. Lewis, R. Leek, A. Harris, and J. O. McGee, "Cytokine regulation of angiogenesis in breast cancer: the role of tumorassociated macrophages," Journal of Leukocyte Biology, vol. 57, no. 5, pp. 747-751, 1995.

[90] D. M. Mosser, "The many faces of macrophage activation," Journal of Leukocyte Biology, vol. 73, no. 2, pp. 209-212, 2003.

[91] G. Solinas, G. Germano, A. Mantovani, and P. Allavena, "Tumor-associated macrophages (TAM) as major players of the cancer-related inflammation," Journal of Leukocyte Biology, vol. 86, no. 5, pp. 1065-1073, 2009.

[92] L. Turner, C. Scotton, R. Negus, and F. Balkwill, "Hypoxia inhibits macrophage migration," European Journal of Immunology, vol. 29, no. 7, pp. 2280-2287, 1999.

[93] F. A. W. Verreck, T. De Boer, D. M. L. Langenberg et al., "Human IL-23-producing type 1 macrophages promote but IL-10-producing type 2 macrophages subvert immunity to (myco)bacteria," Proceedings of the National Academy of Sciences of the United States of America, vol. 101, no. 13, pp. 4560$4565,2004$. 

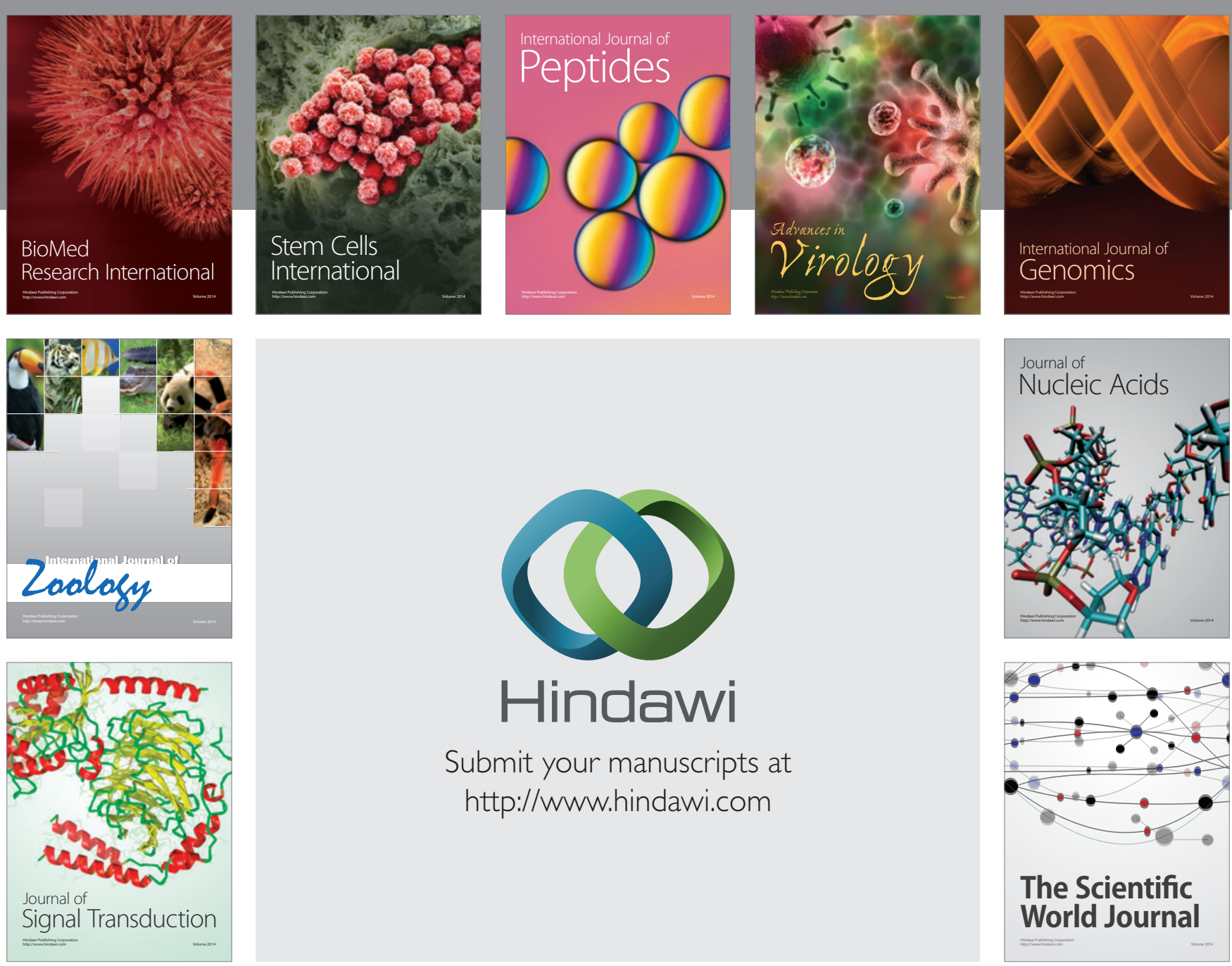

Submit your manuscripts at

http://www.hindawi.com
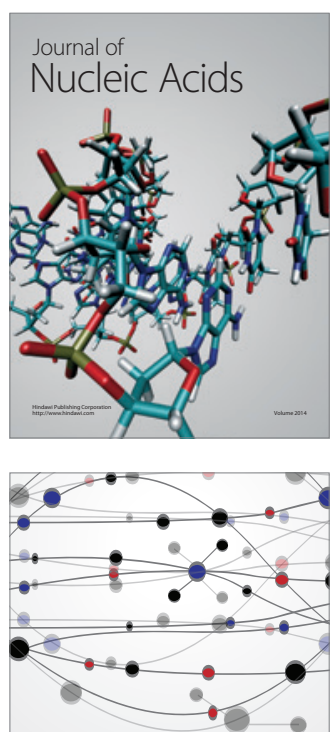

The Scientific World Journal
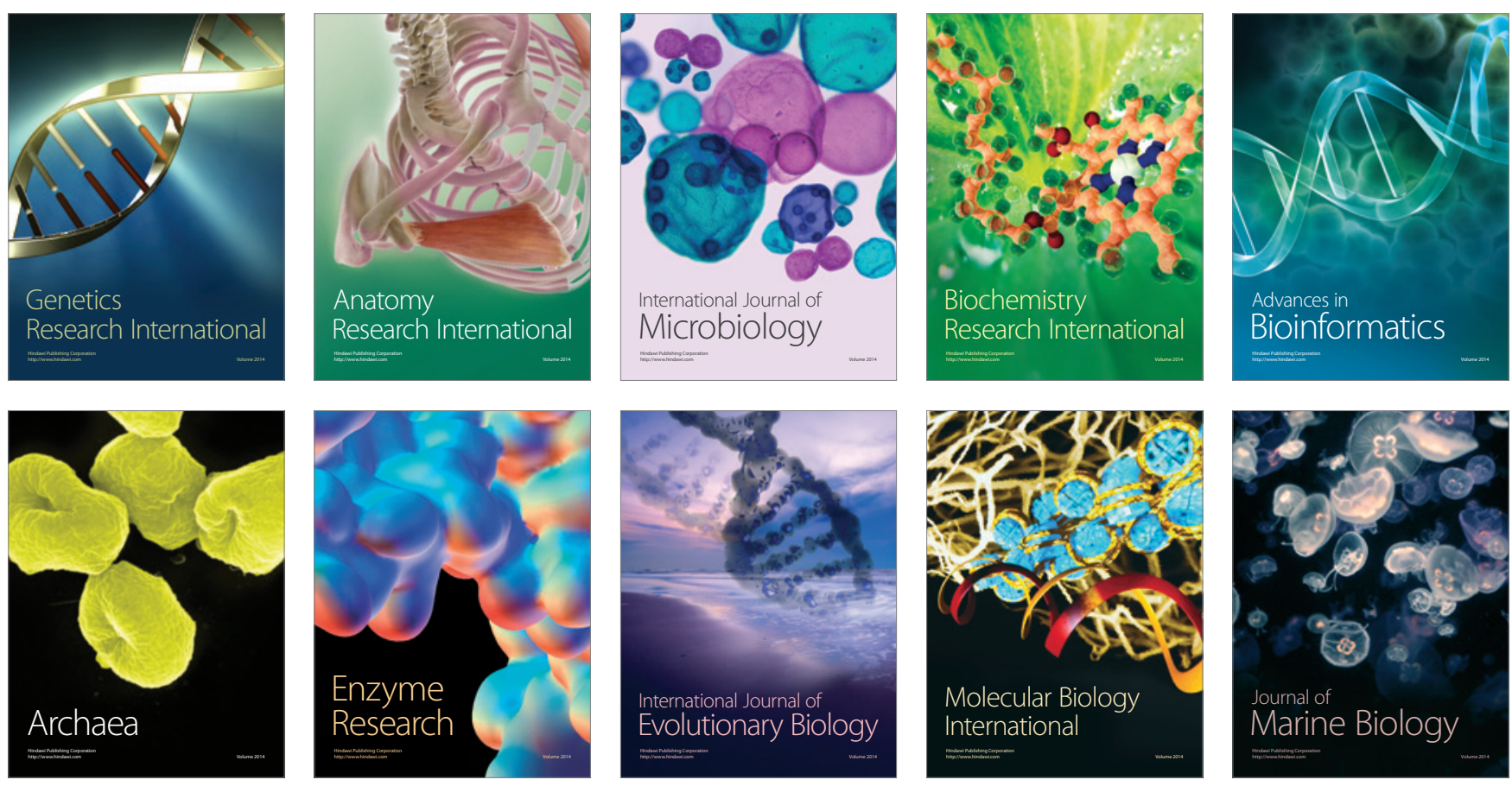